\title{
Molecular Genetics of Androgen-Inducible RP2 Gene Transcription in the Mouse Kidney
}

\author{
CAROL RHEAUME, ${ }^{1}$ KAREN W. BARBOUR, ${ }^{1}$ JULIE TSENG-CRANK, ${ }^{2}$ AND FRANKLIN G. BERGER ${ }^{1 *}$ \\ Department of Biology, University of South Carolina, Columbia, South Carolina $29208,{ }^{1}$ and Division of Biology, \\ California Institute of Technology, Pasadena, California $91125^{2}$
}

Received 4 August 1988/Accepted 28 October 1988

\begin{abstract}
Androgen control of the $R P 2$ gene in the mouse kidney has been modified during evolution. In inbred mice (Mus domesticus), the concentrations of mRNAs encoded by RP2 undergo a 10- to 12-fold induction in response to testosterone; in other Mus species (e.g., Mus hortulanus and Mus caroli), induction ranges from none to about two- to fourfold. In this communication, we show that androgens induced $R P 2$ transcription in $M$. domesticus, although this induction may not have fully accounted for the increase in mRNA levels. Reduced mRNA inducibility in $M$. hortulanus and in several other species was associated with an absence of transcriptional induction. Analysis of an interspecies backcross population indicated that the difference in $R P 2$ inducibility between $M$. domesticus and $M$. hortulanus was due to a single Mendelian locus tightly linked $(0$ of 47 recombinants) to $R P 2$. The $R P 2$ gene was found to contain at least two promoters, only one of which was highly sensitive to testosterone. These results indicate that induction of the $R P 2 \mathrm{mRNAs}$, as well as interspecies variations in $R P 2$ inducibility, are primarily a consequence of effects on this promoter.
\end{abstract}

The evolutionary process results in the generation of interspecies variations in gene expression $(12,13,23,33)$. These variations derive, presumably, from mutations in regulatory elements. The study of naturally occurring alterations in gene expression not only allows identification of these elements but also generates insights into the changes that the elements undergo during evolution. The mouse (genus Mus) has become useful for studies of mammalian gene regulation and evolution. A large number of wellcharacterized species (5-7) provides a pool of variability that has accumulated over a 10-million-year period. Indeed, considerable variation in gene activity has been identified among these species $(2,11,16,25,29)$.

Gene expression in the mouse kidney is regulated by androgens. In proximal tubule cells, testosterone induces the concentrations of a number of gene products; these inductions occur primarily at the mRNA level (see references 9 and 30 for recent reviews; F. G. Berger and G. Watson, Annu. Rev. Physiol., in press). The RP2 gene, which is linked to Gpi-1 on mouse chromosome 7 (14), has become a useful model for androgen-modulated gene expression. $R P 2$ encodes at least two mRNAs that undergo about a 10- to 12-fold induction in the kidneys of female mice treated with testosterone $(3,26)$. These mRNAs, which differ in the lengths of their $3^{\prime}$ untranslated regions (18), encode a polypeptide of 357 amino acids in length as deduced from cDNA sequencing (19). The function of the $R P 2$-encoded protein is not known.

Nuclear run-on assays have indicated that induction of $R P 2$ mRNAs, like the induction of several other androgenregulated mRNAs, is predominantly a posttranscriptional phenomenon, occurring at the level of transcript processing or stability (4). Recently, however, an in vivo assay has been used to show that androgens increase $R P 2$ mRNA synthesis by about 3- to 4-fold (32), which suggests that hormonal induction of transcription may account, at least in part, for the 10- to 12-fold increase in mRNA levels. Since the assay does not distinguish gene transcription from mRNA process-

\footnotetext{
* Corresponding author.
}

ing (32), the role of $R P 2$ transcription in the induction is still unclear.

Although $R P 2$ mRNA induction occurs in all inbred strains of Mus domesticus that have been examined (14; D. Wilson and F. Berger, unpublished data), other Mus species (e.g., Mus hortulanus and Mus caroli) show alterations in the extent of $R P 2$ inducibility (28). We have postulated that induction of the $R P 2 \mathrm{mRNAs}$ arose in two steps during $M u s$ evolution: acquisition of a modest 2- to 4-fold induction was followed by amplification of the response to about 10 -fold (28). Since variations in other androgen-responsive mRNAs do not correlate with that for $R P 2$ (29), it is likely that expression of each mRNA evolved independently. This suggests that cis-acting, gene-specific regulatory elements may be determinants of the evolutionary variations.

In this study, we examined $R P 2$ expression, and the interspecies variations in its androgen inducibility, in more detail. We show that (i) in $M$. domesticus, androgen induction of $R P 2$ transcription does occur and accounts, at least in part, for the increase in mRNA; (ii) reduced $R P 2$ mRNA inducibility in other Mus species reflects altered induction of transcription; (iii) the difference in $R P 2$ inducibility between $M$. domesticus and $M$. hortulanus is due to a single Mendelian gene tightly linked to the $R P 2$ gene; and (iv) $R P 2$ transcription is driven by at least two promoters which differ in sensitivity to hormone.

\section{MATERIALS AND METHODS}

Mice. Inbred $M$. domesticus $\mathrm{DBA} / 2 \mathrm{~J}$ mice were obtained from Jackson Laboratory, Bar Harbor, Maine. M. caroli mice were obtained from the colony of the University of South Carolina or from Verne Chapman, Roswell Park Memorial Institute, Buffalo, N.Y. M. hortulanus mice were also obtained from V. Chapman.

A backcross population from an $M$. domesticus $\times \dot{M}$. hortulanus cross was constructed and supplied by V. Chapman. Since these species do not interbreed in the laboratory, artificial insemination was necessary. Female $\boldsymbol{M}$. domesticus $\mathrm{ICR} / \mathrm{Ha} R P 2^{d / d}$ mice were inseminated with $M$. hortulanus $R P 2^{h / h}$ sperm. Resulting hybrid females were inseminated 


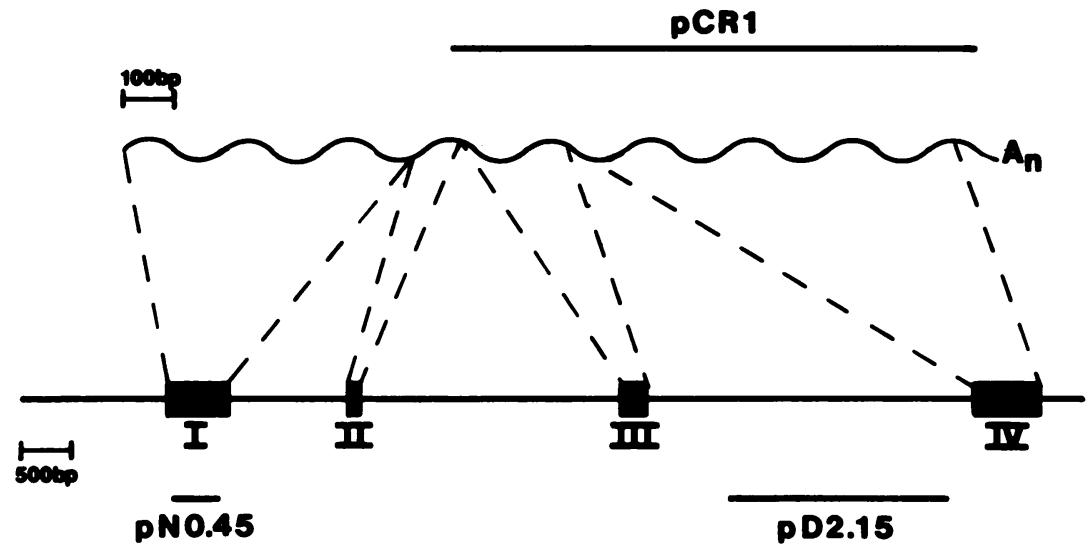

FIG. 1. Structure of the $R P 2$ gene. The four known exons of $R P 2$, numbered I through IV, were deduced from hybridization studies with cDNA clones and DNA sequence analysis (J. Tseng-Crank, unpublished data). The $5^{\prime}$ end of $R P 2$ was identified by King et al. (19); the extreme $3^{\prime}$ end of the gene, encoding the terminal 100 nucleotides of the mRNA, has not been cloned. The locations of regions corresponding to genomic subclones used in this study are shown below the gene. The mRNA is indicated by a wavy line, and the region corresponding to cDNA clone pCR1 is shown above it.

with $M$. hortulanus sperm to generate a small number of $\mathrm{N}_{1}$ backcross animals. The $\mathrm{N}_{1}$ animals were capable of breeding with $M$. hortulanus; therefore, several $\mathrm{N}_{1}$ males heterozygous at the $R P 2$ locus were identified by analysis of tail DNA (17) and mated to $M$. hortulanus females. Of the $66 \mathrm{~N}_{2}$ animals that resulted, 47 were treated with testosterone and analyzed as described below; 19 untreated females were also examined. Testosterone treatment was by subcutaneous application of a $30-\mathrm{mg}$ pellet for 1 week.

Nuclear run-on assays. Transcription rates in isolated nuclei in vitro were measured as described in detail elsewhere (24a). Briefly, nuclei were incubated in the presence of $\left[\alpha-{ }^{32}\right.$ P]UTP under conditions that allow the synthesis of RNA. Labeled RNA was extracted, purified, and hybridized to the appropriate plasmid probes immobilized on nylon filters. After hybridization, filters were washed and observed by autoradiography. Nonspecific background was measured with $\mathrm{pT}_{3} \mathrm{~T}_{7}-18$ or pBR322 DNA. The $R P 2$-specific probes were pCR1, which contains the 1.1-kilobase $R P 2$ cDNA insert of pMK908 (3) in $\mathrm{pT}_{3} \mathrm{~T}_{7}-18$; pN0.45, containing a 450-base-pair fragment of the first exon of the $R P 2$ gene in pUC13; and pD2.15, which contains a 2.15-kilobase fragment of the third intron of the $R P 2$ gene in $\mathrm{pT}_{3} \mathrm{~T}_{7}-18$. The region covered by each of these plasmids is shown in Fig. 1. Single-stranded probes were generated by subcloning plasmid inserts into $\mathbf{M} 13 \mathrm{mp} 8$ or $\mathrm{M} 13 \mathrm{mp} 9$ in both orientations, using standard protocols.

Extraction and analysis of nucleic acids. Total DNA and RNA were isolated from whole tissues by standard methods (28). For Northern (RNA) blot analysis, $15 \mu \mathrm{g}$ of RNA was fractionated on $1.5 \%$ agarose gels containing $2.2 \mathrm{M}$ formaldehyde and transferred to a nylon membrane. The membrane was hybridized to an $R P 2$ probe, which was usually the purified 1.1-kilobase cDNA insert of pCR1 labeled by nick translation. Hybridizing RNAs were observed by autoradiography. For Southern blotting, $10 \mu \mathrm{g}$ of DNA was digested with EcoRI, fractionated on $1.0 \%$ agarose gels, blotted onto a nylon membrane, and hybridized to the $R P 2$ probe. Hybridizing fragments were observed by autoradiography.

cDNA cloning. Poly(A)-containing RNA from $M$. caroli liver was used to prepare a cDNA library in $\lambda$ gt 10 , using procedures described by Gubler and Hoffman (15). Briefly, first-strand cDNA synthesis was performed with Moloney murine leukemia virus reverse transcriptase, and the RNA template strand was converted into DNA with RNase $H$ and DNA polymerase $\mathrm{I}$. The resulting double-stranded cDNA was filled in with the Klenow fragment of DNA polymerase I, ligated to EcoRI linkers, and chromatographed on a Bio-Gel A-15M column (Bio-Rad Laboratories, Richmond, Calif.). All enzymes were purchased from Bethesda Research Laboratories, Inc., Gaithersburg, Md. Fractions containing the longest $\mathrm{cDNAs}$ were pooled, ligated to $\lambda \mathrm{gt} 10$, and packaged by using a Gigapak extract (Stratagene). Starting with $250 \mathrm{ng}$ of size-fractionated cDNA, we obtained $1.3 \times$ $10^{6}$ recombinant plaques. The library was screened by the method of Benton and Davis (1), using the insert of plasmid pCR1 as a probe. Positive plaques were purified, and the cDNA inserts were subcloned into $\mathrm{pT}_{3} \mathrm{~T}_{7}-18$.

S1 nuclease protection assays. A 129 -base-pair $P v u I I$ fragment (see text) was $5^{\prime}$-end-labeled with $\mathrm{T} 4$ polynucleotide kinase; $10,000 \mathrm{cpm}$ of probe $(\sim 1 \mathrm{ng})$ was hybridized to 100 $\mu \mathrm{g}$ of total RNA in a $25-\mu$ l reaction mixture containing 40 mM PIPES [piperazine- $N, N^{\prime}$-bis(2-ethanesulfonic acid); $\mathrm{pH}$ 6.8], $0.4 \mathrm{M} \mathrm{NaCl}$, and $1 \mathrm{mM}$ disodium EDTA. After overnight incubation at $50^{\circ} \mathrm{C}, 250 \mu \mathrm{l}$ of $30 \mathrm{mM}$ sodium acetate (pH 4.75) containing $0.25 \mathrm{M} \mathrm{NaCl}, 1 \mathrm{mM} \mathrm{ZnCl}_{2}, 5 \%$ glycerol, and $150 \mathrm{U}$ of $\mathrm{S} 1$ nuclease $(53,000 \mathrm{U} / \mathrm{ml}$; Pharmacia, Inc., Piscataway, N.J.) was added. S1 digestion (30 min at $37^{\circ} \mathrm{C}$ ) was followed by addition of $25 \mu \mathrm{l}$ of $0.6 \mathrm{M}$ Tris hydrochloride ( $\mathrm{pH} 8$ ) containing $2 \%$ sodium dodecyl sulfate, $55 \mathrm{mM}$ disodium EDTA, and $0.2 \mathrm{mg}$ of Escherichia coli tRNA per $\mathrm{ml}$. After phenol extraction and ethanol precipitation, the RNA was suspended in $15 \mu$ l of deionized formamide, heated at $65^{\circ} \mathrm{C}$ for $10 \mathrm{~min}$, and subjected to electrophoresis through a $10 \%$ urea-polyacylamide gel. After electrophoresis, the gel was soaked in $10 \%$ acetic acid for $30 \mathrm{~min}$, dried, and observed by autoradiography.

DNA sequencing. Sequencing was done by the chain termination method, using modified T7 DNA polymerase, as described in a kit from United States Biochemical Corporation, Cleveland, Ohio.

\section{RESULTS}

Androgen induction of $\boldsymbol{R P 2}$ transcription. Earlier studies led us to conclude that androgen induction of several kidney mRNAs, including those encoded by the $R P 2$ gene, was 


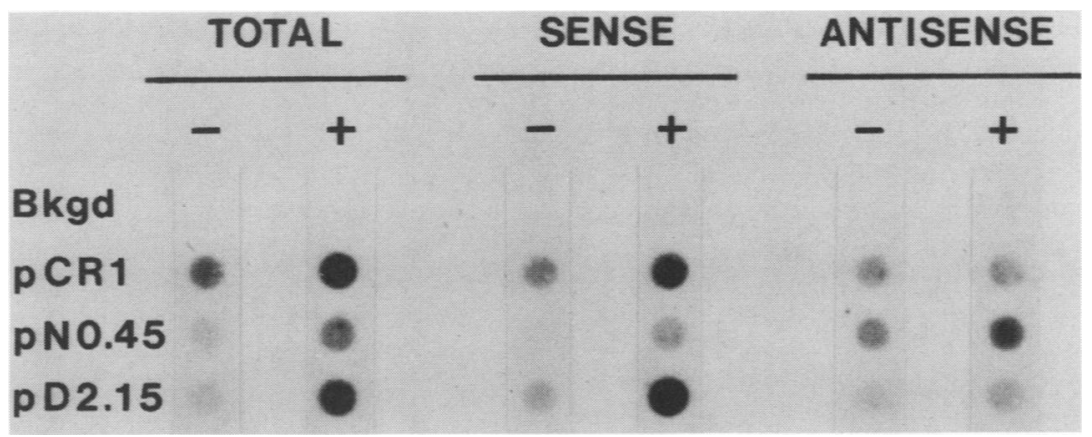

FIG. 2. Nuclear run-on analysis of $R P 2$ gene transcription in $M$. domesticus. Nuclei were isolated from kidneys of control ( -$)$ and testosterone-treated (+) $M$. domesticus DBA/2J mice, and $R P 2$ transcription was measure in vitro (see Materials and Methods). Genomic subclones pN0.45 and pD2.15 and cDNA clone pCR1 served as probes; double-stranded plasmids were used to measure total transcription, and appropriate M13 clones of inserts from these plasmids were used to measure sense and antisense transcription. Nonspecific background hybridization (Bkgd) was assessed with $\mathrm{pBR} 322$ or $\mathrm{pT}_{3} \mathrm{~T}_{7}-18 \mathrm{DNA}$.

primarily posttranscriptional (4). This conclusion was based on the lack of detectable androgen-mediated increases in $R P 2$ transcription as measured in nuclear run-on assays. The kinetics of induction and deinduction after hormone administration and withdrawal, respectively, were consistent with a major effect of androgens on mRNA turnover (4). Several observations prompted us to reexamine this issue. First, later nuclear run-on experiments, which made use of different methods for extraction and detection of specific RNAs synthesized by isolated nuclei, consistently showed small but significant increases in $R P 2$ transcription. Second, Watson and Paigen (32) measured an induction of $R P 2$ mRNA synthesis in vivo in response to androgens. Third, in unrelated studies we noted that specific regions within certain genes were aberrantly transcribed in isolated nuclei, resulting in sense as well as antisense transcripts that did not accumulate in the tissues from which the nuclei were derived (24a); this phenomenon can be a source of error in transcription rate measurements. We therefore repeated nuclear run-on analysis of $R P 2$ transcription, measuring both sense and antisense transcription from several regions within the gene.

Kidney nuclei were isolated from control and androgentreated $M$. domesticus $\mathrm{DBA} / 2 \mathrm{~J}$. The nuclei were incubated in the presence of $\left[\alpha-{ }^{32} \mathrm{P}\right] \mathrm{UTP}$ for $45 \mathrm{~min}$, and the ${ }^{32} \mathrm{P}$-labeled RNA was extracted, purified, and hybridized to $R P 2$-specific plasmids immobilized on nylon filters (see Materials and Methods and reference 24a). The plasmid probes represented cDNA (pCR1) and genomic (pN0.45 and pD2.15) clones corresponding to RP2 sequences (Fig. 1). Each plasmid hybridized to RNA that was synthesized at higher rates in nuclei from androgen-treated animals (Fig. 2), which indicated an effect of the hormone on $R P 2$ transcription. It was consistently observed that induction was greatest with pD2.15, which represents a subclone of the third intron (Fig. $1)$; induction measured with the cDNA clone pCR1 or with the exon 1 subclone pN0.45 was always more difficult to detect.

The differences in transcription induction measured with the three $R P 2$ probes might have been a consequence of antisense RNA synthesis occurring within specific regions of the gene, thereby obscuring sense transcription from these regions. This possibility was tested by using single-stranded probes, which were generated by cloning each of the $R P 2$ specific inserts into M13 in both orientations. For each probe, sense transcription was induced in nuclei from androgen-treated mice (Fig. 2). RNA hybridizing to pN0.45 and
pD2.15 was induced to a greater extent with sense-specific than with double-stranded probes; however, as with the double-stranded plasmids, the extents of inducibility were not the same with each probe (compare pCR1 with pN0.45 or pD2.15 in Fig. 2). Significant levels of antisense transcription, which were generally refractory to androgen treatment, were observed (Fig. 2).

We conclude from these results that $R P 2$ transcription is induced by testosterone. However, by densitometry we were able to measure at most only a three- to fivefold induction. Therefore, increases in transcription did not completely account for the 10 - to 12 -fold increase in mRNA. The lack of observable induction in previous studies (4) was due, at least in part, to the use of double-stranded plasmids, which detected antisense transcription within the $R P 2$ gene and obscured the measurement of sense transcription. Furthermore, plasmid pMK908, which was used in the earlier work, contains the same cDNA insert as does pCR1 (see Materials and Methods); pCR1 allowed barely detectable levels of induction to be measured (Fig. 2).

Lack of transcriptional induction in species with low $R P 2$ mRNA inducibility. Several Mus species exhibit reduced $R P 2$ mRNA inducibility in response to androgens (28). For example, induction in $M$. hortulanus is only two- to fourfold (28). To determine whether such variation reflects alterations in transcription, kidney nuclei were isolated from both control and testosterone-treated $M$. hortulanus mice, and $R P 2$ transcription was measured in the nuclear run-on assay. Double-stranded probes, as well as sense and antisense single-stranded probes, were used. No induction of $R P 2$ transcription was observed in $M$. hortulanus (Fig. 3) even with sense-specific probes. Considerable antisense transcription was seen, paralleling that observed in $M$. domesticus. Similar results were obtained for $M$. caroli and Mus cookii (data not shown). Thus, variations in androgeninducible $R P 2$ mRNA expression among Mus species reflect changes at the transcriptional level. The lack of detectable transcription induction in these species suggests that residual mRNA induction, which is as much as two- to fourfold in $M$. hortulanus (28), may occur through a posttranscriptional mechanism.

Evidence that the variation in inducibility between $M$. domesticus and $M$. hortulanus is the consequence of a single Mendelian locus. Because of its greater androgen inducibility, $M$. domesticus contains higher $R P 2$ mRNA levels after hormone treatment than does $M$. hortulanus (28). Segregation of the mRNA inducibility phenotype was examined in 


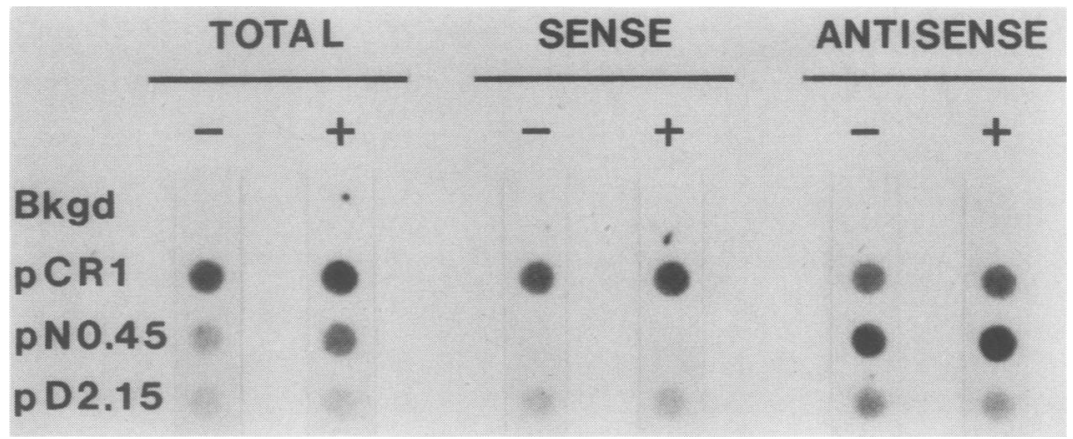

FIG. 3. Nuclear run-on analysis of $R P 2$ gene transcription in $M$. hortulanus. $R P 2$ transcription was measured in nuclei from $M$. hortulanus exactly as described for $M$. domesticus in the legend to Fig. 2. Bkgd, Background hybridization.

backcross animals derived from an $M$. domesticus $\times M$. hortulanus interspecies cross. Kidney RNA was extracted from each of $\mathbf{4 7}$ testosterone-treated animals representing a second backcross generation (see Materials and Methods), and the $R P 2$ mRNA levels were determined by Northern blotting. Segregation of the $R P 2$ structural gene was measured in the same animals. The $M$. domesticus mice used in the cross carry the $R P 2^{d / d}$ genotype (14); $M$. hortulanus carries the $R P 2^{h / h}$ genotype, which is distinguishable from $R P 2^{d / d}$ by Southern blotting of EcoRI-digested DNA (29; Fig. 4).

The $R P 2^{h / d}$ segregants (Fig. 5, lanes 1,2 , and 5) contained higher mRNA levels than did the $R P 2^{\text {h/h }}$ segregants (lanes 3 and 4). The high levels in $R P 2^{h / d}$ mice were intermediate between those of $M$. domesticus and $M$. hortulanus. The low levels in $R P 2^{h / h}$ mice were similar to levels in the $M$. hortulanus parent. The correlation between the $R P 2$ genotype and mRNA levels occurred in all 47 backcross progeny: 23 animals were $R P 2^{h / d}$ and contained high mRNA levels, while 24 animals were $R P 2^{h / h}$ and contained low mRNA levels. Thus, a single Mendelian locus is the primary determinant of the difference in $R P 2$ inducibility between $M$. domesticus and $M$. hortulanus. This element is linked to the $R P 2$ gene itself.

There was no difference in $R P 2$ mRNA expression between $R P 2^{h / d}$ and $R P 2^{h / h}$ segregants among 19 untreated female backcross progeny (data not shown). This finding is

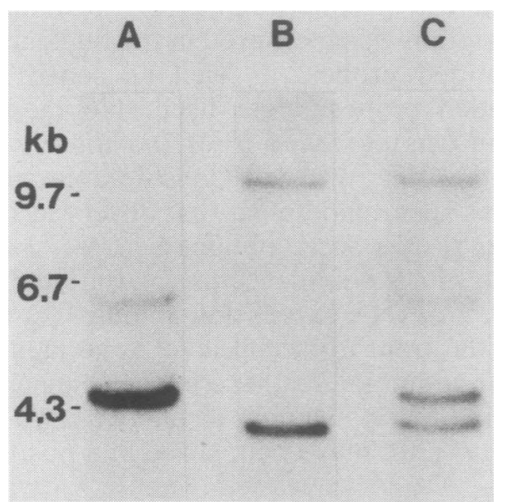

FIG. 4. Southern blot analysis of the $R P 2^{h / h}$ and $R P 2^{d / d}$ alleles. Liver DNA from $M$. domesticus DBA/2J RP2 ${ }^{d / d}$ (lane A), $M$. hortulanus RP2 ${ }^{h / h}$ (lane B), and a hybrid between the two $\left(R P 2^{h / d}\right.$, lane C) were digested with $E c o R I$ and analyzed for $R P 2$ sequences by Southern blotting. The 1.1-kilobase $R P 2$-specific cDNA insert of pCR1 was used as a probe. Fragment sizes in kilobases (kb) are indicated to the left. consistent with the observation that basal $R P 2$ mRNA concentrations do not differ significantly between the species. Therefore, the regulatory element that distinguishes $R P 2$ expression in $M$. domesticus and $M$. hortulanus specifically controls hormone-inducible, but not basal, mRNA expression.

Multiple promoters for the $R P 2$ gene differ in sensitivity to androgens. We initiated molecular analysis of the $M$. caroli $R P 2$ gene by isolation of a cDNA clone (pKB30) from a $\lambda$ t10 library. When the restriction map of the pKB30 insert was aligned with that of $M$. domesticus (Fig. 6A), it was observed that the $5^{\prime}$ end of the former was 25 to 30 nucleotides longer than expected on the basis of the previously determined position of the +1 start site of the $M$. domesticus transcript. Several explanations for this result

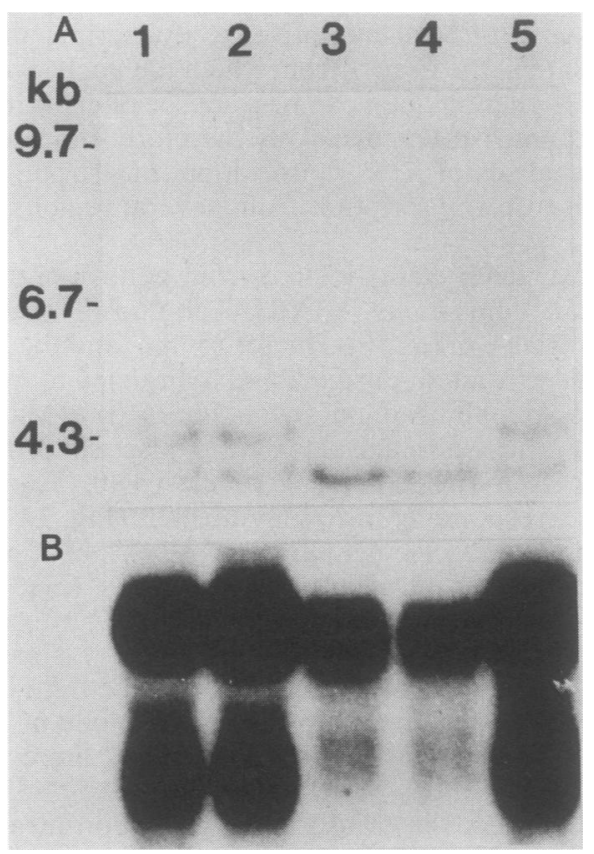

FIG. 5. Cosegregation of the $R P 2$ structural gene and the $R P 2$ mRNA phenotype in an interspecies backcross. Five representative progeny from the second backcross generation of an $M$. domesticus $\times M$. hortulanus cross (see text) were treated with testosterone. The $R P 2$ gene was analyzed in each by Southern blotting of EcoRIdigested liver DNA (A); the $R P 2$ mRNAs were measured by Northern blot analysis of total RNA (B). The cDNA insert of pCR1 was used as a probe for both blots. Fragment sizes in kilobases (kb) are indicated to the left. 

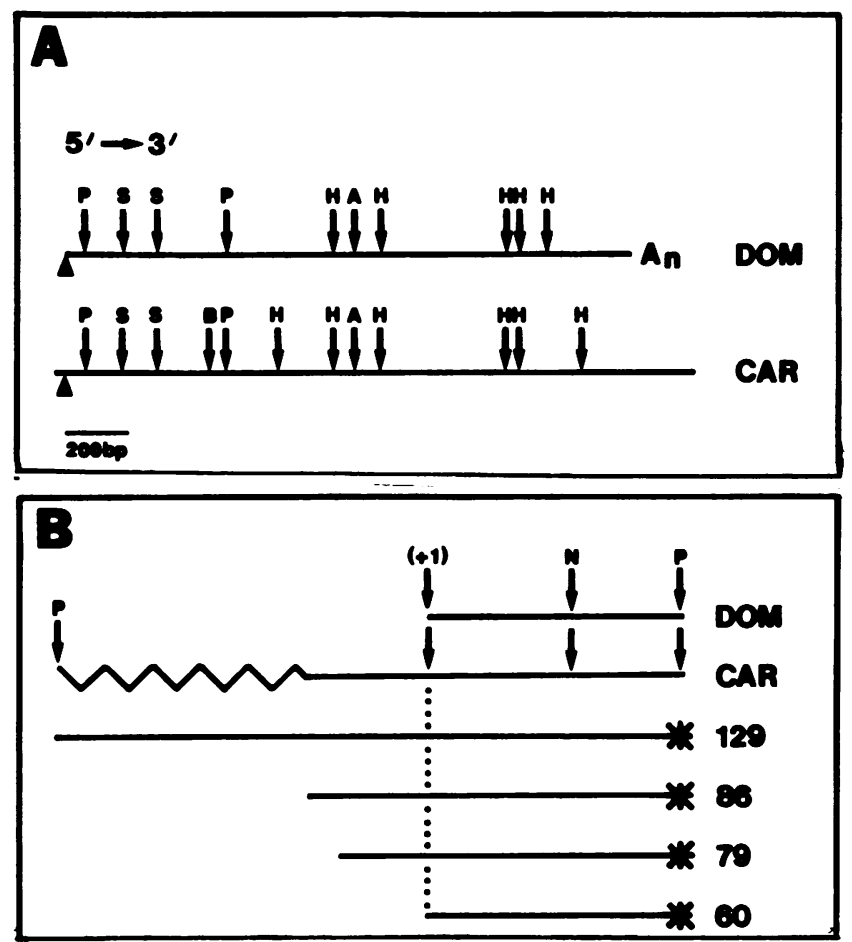

FIG. 6. (A) Restriction maps of $R P 2$ cDNAs from $M$. domesticus and $M$. caroli. The $M$. domesticus (DOM) map, representing the full-length mRNA, was taken from published data $(18,19)$; the $M$. caroli (CAR) map represents the insert of cDNA plasmid pKB30 (see text). The two are aligned by restriction sites. $\Delta,+1$ start site for the mRNA (19), which is extended by 25 to 30 nucleotides in pKB30. Abbreviations for restriction enzymes: P, PvuII; S, SmaI; H, HinfI; A, AccI. (B) Probes for S1 nuclease protection. The 5' end of the $R P 2$ cDNA from $M$. domesticus (DOM) is shown from the start site at +1 to the Pvull site at +60 . The $5^{\prime}$ end of the $M$. caroli (CAR) cDNA in pKB30 is shown from the Pvull site within the cloning vector $(m)$ to the PvuII site homologous to position +60 of the $M$. domesticus sequence. The 129-base probe used in S1 protection experiments is shown, along with the 86-, 79-, and 60-base protected fragments (see text). *, Protected end, located at the PvuII site. Abbreviations for restriction enzymes: P, PvulI; N, NaeI.

are possible. The original assignment of the +1 site, which was based on primer extension assays (19), may be incorrect. Alternatively, the 25 to 30 extra nucleotides may have resulted from some sort of cloning artifact. Finally, there may be species-specific promoters driving $R P 2$ transcription and generating $5^{\prime}$-end variation.

To distinguish among these possibilities, we used the $M$. caroli cDNA as a probe in S1 nuclease protection assays. A 129-base-pair PvuII fragment, containing the extreme $5^{\prime}$ end of the cDNA, was isolated and end labeled. One end of the probe corresponds to the $P v u I I$ site located at position +60 relative to the mRNA cap site (19); the other end is within the multiple cloning site of the $\mathrm{pT}_{3} \mathrm{~T}_{7}-18$ vector (Fig. $6 \mathrm{~B}$ ). The probe was hybridized to total kidney RNA from control and androgen-treated mice, digested with $\mathrm{S} 1$ nuclease, and subjected to polyacrylamide gel electrophoresis (Fig. 7). RNA from control $M$. domesticus protected fragments of 86 , 79 , and 60 bases in length. The largest of these corresponded to the entire cDNA probe from the $P v u I I$ site at +60 through the extra nucleotides at the $5^{\prime}$ end (Fig. 6B). The 60-base fragment is expected for RNA that initiates at the +1 site.

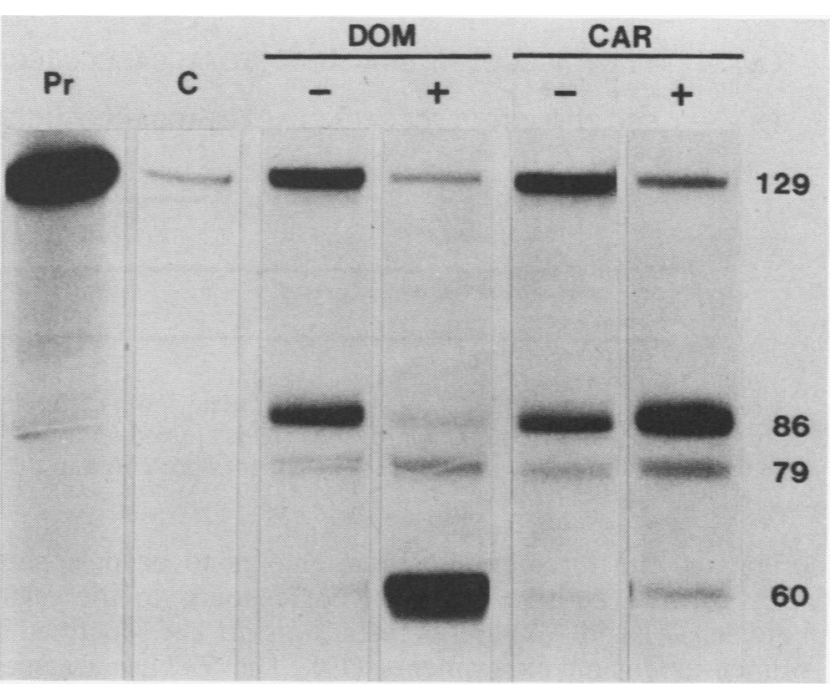

FIG. 7. Results of $\mathbf{S} 1$ protection experiments showing that multiple promoters for the $\boldsymbol{R P} \mathbf{2}$ gene differ in sensitivity to androgens. Total kidney RNAs from control $(-)$ and testosterone-treated $(+)$ $M$. domesticus DBA/2J (DOM) and $M$. caroli (CAR) were hybridized to the end-labeled 129-base probe (Fig. 6B) and digested with $S 1$ nuclease; protected fragments were observed after gel electrophoresis and autoradiography. Pr, Probe; C, control containing no added RNA. Sizes of the various fragments (in bases) are shown to the right.

RNA from androgen-treated mice protected the same three fragments, although at different relative levels. The 60 -base fragment was induced in response to hormone, whereas the 86-base fragment was repressed. These patterns were reproducible and were observed with either total or poly(A)containing RNA. Thus, transcription of the $R P 2$ gene is controlled by at least two promoters that differ in sensitivity to testosterone regulation. Hormonal induction of the $\boldsymbol{R P} 2$ mRNAs appears to be due to the promoter that drives transcription from the +1 start site (19).

$S 1$ protection experiments were performed with kidney RNA from $M$. caroli (Fig. 7). The pattern in untreated animals was indistinguishable from that in $M$. domesticus; androgens had only small effects on the levels of protection of the three fragments. This finding is in accordance with the mRNA inducibility phenotype in this species (28).

The most striking difference between $M$. domesticus and $M$. caroli was the impaired hormonal induction of RNA initiated at the +1 start site (i.e., that represented by the 60-base fragment). This was found for all Mus species exhibiting reduced mRNA induction, including $M$. hortulanus, $M$. cookii, Mus saxicola, Mus pahari, and Mus minutoides (data not shown). Although alterations in the levels of RNAs initiated at the other site(s) were consistently detectable, it is clear that the interspecies variations in $R P 2 \mathrm{mRNA}$ inducibility are primarily a consequence of effects on transcripts derived from the +1 start site.

The sequence of the $5^{\prime}$ end of the $M$. caroli cDNA insert (Fig. 8B) was aligned with $M$. domesticus $R P 2$ genomic sequences from position -26 in the $5^{\prime}$-flanking region to the $P v u I I$ site at +60 (Fig. 8A). The two sequences were found to be homologous between nucleotides -19 and +60 ; the most 5'-proximal 7 nucleotides of the cDNA were not homologous to sequences within this region of the gene or to any sequences up to nucleotide -170 . These sequence data extend the results of the $S 1$ protection assays and allow the 
(A)

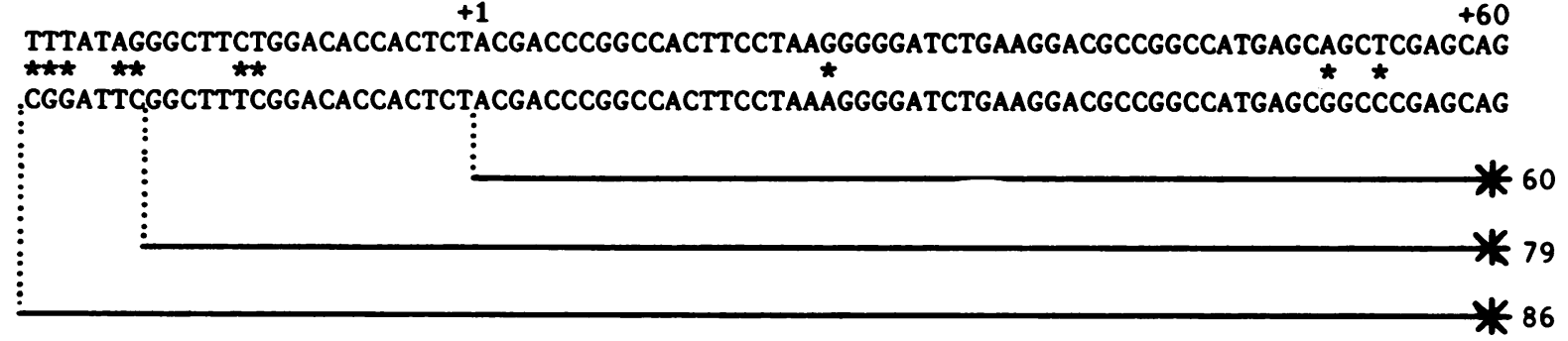

FIG. 8. Sequence of the $5^{\prime}$ end of the $R P 2$ gene and its relationship to $M$. caroli cDNA. The region between -26 and the $P v u I I$ site at +60 within the $R P 2$ gene from $M$. domesticus (A) is aligned with the $5^{\prime}$ end of the cDNA insert of pKB30 (B), which was isolated from $M$. caroli (see text). ${ }^{*}$, Nucleotide differences. Fragments protected in the S1 nuclease assays of Fig. 7 are indicated.

origins of the three protected fragments to be designated (Fig. 8). The 60-base fragment corresponds to the region between +1 and +60 and defines the start site identified by primer extension experiments (19). The 79-base fragment corresponds to the region between -19 and +60 ; interestingly, the $R P 2$ gene sequence immediately upstream of -19 (i.e., TTTATAG) fits very well with that of a splice acceptor site, which suggests the presence of an intron-exon boundary. The 86-base fragment corresponds to the region between -19 and +60 attached to an additional 7 nucleotides derived from an exon located upstream of position -170 . Thus, $R P 2$ mRNA expression is derived from at least two promoters: a downstream promoter initiates transcription at the +1 site, while one or more upstream promoters generate two additional transcripts that may be spliced differently.

\section{DISCUSSION}

The nuclear run-on experiments described above indicate that transcription of the $R P 2$ gene is induced by testosterone in the mouse kidney; the extent of transcription induction is less than the increase in mRNA levels, which suggests control at the posttranscriptional level. This conclusion is similar to that drawn by Watson and Paigen (32) on the basis of in vivo RNA synthesis measurements. Earlier transcription studies, making use of double-stranded probes, failed to detect an effect of androgens on $R P 2$ transcription (4). One reason for the discrepancy lies in the existence of constitutive antisense transcription within $R P 2$ (Fig. 2), which is detected with double-stranded probes and obscures the measurement of androgen-regulated sense transcription. However, such antisense transcription does not fully account for the inability to measure induction, since the effect of hormone on sense transcription varies within $R P 2$. For example, the induction of sense-specific RNA corresponding to pCR1 is significantly less than that corresponding to pN0.45 or pD2.15 (Fig. 2). This finding may reflect constitutive sense transcription from specific regions within the gene, a phenomenon that we have observed for other genes and whose biological significance remains unclear (24a).

$R P 2$ transcription in several species is not induced in response to testosterone even when single-stranded probes are used in the analyses (Fig. 3). Thus, the reduced inducibility of the $R P 2$ mRNAs in these species (28) reflects a loss of hormone-mediated induction of transcription. Since these species still have measurable (i.e., two to fourfold) mRNA induction (28), it is possible that a posttranscriptional effect of androgens on the $R P 2$ mRNA level is retained.

Previous analysis of $R P 2$ inducibility in a variety of Mus species indicated that the response arose in two separate steps during evolution (28). It is possible that the first step occurred at the posttranscriptional level, since no induction of $R P 2$ gene transcription occurs in several species yet the $R P 2$ mRNAs undergo a two- to fourfold increase. The second step, which amplified the response to about 10- to 12 -fold (28), could represent the addition of a transcriptional component. This possibility implies that transcriptional and posttranscriptional effects of androgens evolved independently from separate genetic events.

The results of an interspecies genetic cross indicated that $R P 2$ induction is controlled by a single Mendelian gene that is linked ( 0 of 47 recombinants) to the $R P 2$ structural gene. As deduced from this cross, the distance between the $R P 2$ gene and its regulatory element is between 0 and 6.2 centimorgans at the $95 \%$ confidence level. Therefore, the regulatory element may be within $R P 2$ or as far away as 6 centimorgans. It is likely that this element is cis acting, as are most regulatory loci governing androgen inducibility (21, $23,31)$.

Using $\mathrm{S} 1$ protection assays, we have demonstrated the existence of at least two promoters for the $R P 2$ gene. One, which corresponds to that identified by King et al. (19), who used primer extension assays, is highly sensitive to testosterone (Fig. 7) and is responsible for most of the $R P 2$ mRNA induction. The response of this promoter to androgen is observed in all mice that undergo maximal $R P 2$ mRNA induction, including a number of inbred strains and the species Mus spretus (data not shown). Reduced mRNA induction in $M$. caroli, as well as in several other species (28), is due primarily to alterations in the function of this promoter (Fig. 7 and data not shown). Androgens do have small but detectable effects on RNAs derived from the other promoter(s). For example, we observed repression of RNA represented by the 86-base S1-protected fragment in DBA/2J mice (Fig. 7); interestingly, this repression did not occur in other inbred mice (data not shown), which suggests that its occurrence may be polymorphic within $M$. domesticus. In general, expression of the transcripts corresponding to the 79- and 86-base fragments is less sensitive to hormone and plays little role in the interspecies variations.

At this point, we cannot say exactly how many promoters exist. The 86- and 79-base S1-protected fragments, which may represent differentially spliced RNAs, could derive either from two separate promoters or from alternative splicing of a precursor transcript initiated from a single promoter. The analyses required to distinguish between these possibilities are in progress.

The molecular mechanisms by which androgens modulate gene transcription are not clear. Information to date suggests that genetic elements within or near the structural gene play an important role $(8,10,20,22,24,27)$. Several studies have 
indicated that androgen regulation of mouse mammary tumor virus expression is conferred by a sequence, termed the hormone response element, that is also responsible for progesterone and glucocorticoid regulation of virus transcription $(10,24)$; this element is located upstream of the transcription initiation site and may be a binding site for the androgen receptor. We suspect that androgen regulation of the $R P 2$ promoter is due to sequences in the 5 -flanking region of the gene. Hormonal induction of $R P 2$ transcription may be a consequence of interactions between these sequences and specific trans-acting factors whose activities or concentrations (or both) are controlled by testosterone. The androgen receptor may be one such factor. Of great interest will be the role, if any, of these interactions in the evolutionary modification of the response of the $R P 2$ gene to androgens.

\section{ACKNOWLEDGMENTS}

We thank V. Chapman for providing the backcross animals, B. Parker and C. Schonfeld for technical assistance, and K. French for secretarial work.

This work was supported by Public Health Service grant DK37265 from the National Institute of Diabetes and Digestive and Kidney Diseases.

\section{LITERATURE CITED}

1. Benton, W. D., and R. W. Davis. 1973. Screening $\lambda$ gt recombinant clones by hybridization to single plaques in situ. Science 196:180-182.

2. Berger, F. G., and H. Baumann. 1985. An evolutionary switch in tissue-specific gene expression: abundant expression of $\alpha_{1^{-}}$ antitrypsin in the kidney of a wild mouse species. J. Biol. Chem. 260:1160-1165.

3. Berger, F. G., K. W. Gross, and G. Watson. 1981. Isolation and characterization of a DNA sequence complementary to an androgen-inducible messenger RNA from mouse kidney. J. Biol. Chem. 256:7006-7013.

4. Berger, F. G., D. Loose, H. Meisner, and G. Watson. 1986. Androgen induction of messenger RNA concentrations in mouse kidney is post-transcriptional. Biochemistry 25:1170 1175.

5. Bonhomme, F. 1986. Evolutionary relationships in the genus Mus. Curr. Top. Microbiol. Immunol. 127:19-34.

6. Bonhomme, F., J. Catalan, J. Britton-Davidian, V. M. Chapman, K. Moriwaki, E. Nevo, and L. Thaler. 1984. Biochemical diversity and evolution in the genus Mus. Biochem. Genet. 22:275-303.

7. Callahan, R., and G. J. Todaro. 1978. Four major endogenous retrovirus classes each genetically transmitted in various species of Mus, p. 689-713. In H. C. Morse III (ed.), Origins of inbred mice. Academic Press, Inc., New York.

8. Cato, A. C. B., D. Henderson, and H. Ponta. 1987. The hormone response element of the mouse mammary tumor virus DNA mediates the progestin and androgen induction of transcription in the proviral long terminal repeat region. EMBO J. 6:363-368.

9. Catterall, J. F., K. K. Kontula, C. S. Watson, P. J. Seppanen, B. Funkenstein, E. Melanitou, N. J. Hickok, C. W. Bardin, and O. A. Janne. 1986. Regulation of gene expression by androgens in murine kidney. Recent Prog. Horm. Res. 42:71-108.

10. Darbre, P., M. Page, and R. J. B. King. 1986. Androgen regulation by the long terminal repeat of mouse mammary tumor virus. Mol. Cell. Biol. 6:2847-2854.

11. Dickinson, D. P., K. W. Gross, N. Piccini, and C. M. Wilson. 1984. Evolution and variation of renin genes in mice. Genetics 108:651-667.

12. Dickinson, W. J. 1980. Evolution of patterns of gene expression in Hawaiian picture-winged Drosophila. J. Mol. Evol. 16:73-94.

13. Dickinson, W. J., R. G. Rowan, and M. D. Brennan. 1984. Regulatory gene evolution: adaptive differences in expression of alcohol dehydrogenase in Drosophila melanogaster and Drosophila simulans. Heredity 52:215-225.

14. Elliott, R. W., and F. G. Berger. 1983. DNA sequence polymorphism in an androgen-regulated gene is associated with alterations in the encoded RNAs. Proc. Natl. Acad. Sci. USA 80:501-504.

15. Gubler, U., and B. J. Hofiman. 1983. A simple and efficient method for generating cDNA libraries. Gene 25:263-269.

16. Hammer, M. F., and A. C. Wilson. 1987. Regulatory and structural genes for lysozymes of mice. Genetics 115:521-533.

17. Hogan, B., F. Constantini, and E. Lacy. 1986. Manipulating the mouse embryo: a laboratory manual. Cold Spring Harbor Laboratory, Cold Spring Harbor, N.Y.

18. King, D., L. D. Snider, and J. B. Lingrel. 1986. Polymorphism in an androgen-regulated mouse gene is the result of the insertion of a B1 repetitive element into the transcription unit. Mol. Cell. Biol. 6:209-217.

19. King, D., Y. H. Sun, and J. B. Lingrel. 1986. Amino acid sequence of the testosterone-regulated mouse kidney $R P 2$ protein deduced from its complementary DNA sequence. Nucleic Acids Res. 14:5159-5170.

20. Loreni, F., J. Stavenhagen, M. Kalfi, and D. M. Robins. 1988. A complex androgen-responsive enhancer resides 2 kilobases upstream of the mouse Slp gene. Mol. Cell. Biol. 8:2350-2360.

21. Lund, S. D., D. Miller, V. Chapman, and R. E. Ganschow. 1988. Androgen regulation of murine $\beta$-glucuronidase expression: identification and characterization of a nonresponse variant. Genetics 119:151-156.

22. Page, M. J., and M. G. Parker. 1983. Androgen-regulated expression of a cloned rat prostatic $\mathrm{C} 3$ gene transfected into mouse mammary tumor cells. Cell 32:495-502.

23. Paigen, K. 1979. Acid hydrolases as models of genetic control. Annu. Rev. Genet. 13:417-466.

24. Parker, M. G., P. Webb, M. Needham, R. White, and J. Ham. 1987. Identification of androgen response elements in mouse mammary tumor virus and the rat prostate C3 gene. J. Cell. Biochem. 35:285-292.

24a.Rheaume, C., J. J. Latimer, H. Baumann, and F. G. Berger. 1988. Tissue- and species-specific regulation of murine $\alpha_{1-}^{-}$ antitrypsin gene transcription. J. Biol. Chem. 263:15118-15121.

25. Sampsell, B. M., and W. A. Held. 1985. Variation in the major urinary protein multigene family in wild-derived mice. Genetics 109:549-568.

26. Snider, L. D., D. King, and J. B. Lingrel. 1985. Androgen regulation of MAK mRNAs in mouse kidney. J. Biol. Chem. 260:9884-9893.

27. Stavenhagen, J., F. Loreni, C. Hemenway, M. Kalfi, and D. M. Robins. 1987. Molecular genetics of androgen-dependent and -independent expression of mouse sex-limited protein. Mol. Cell. Biol. 7:1716-1724.

28. Tseng-Crank, J., and F. G. Berger. 1987. Evolution of steroidinducible RP2 mRNA expression in the mouse kidney. Genetics 116:593-599.

29. Tseng-Crank, J., C. Schonfeld, and F. G. Berger. 1988. Evolution of androgen-regulated mRNA expression in mouse kidney. Mol. Biol. Evol. 5:442-454.

30. Watson, C. S., D. Salomon, and J. F. Catterall. 1984. Structure and expression of androgen-regulated genes in mouse kidney. Ann. N.Y. Acad. Sci. 438:101-114.

31. Watson, G., and K. Paigen. 1987. Genetic variations in the kinetic constants that describe $\beta$-glucuronidase mRNA induction in androgen-treated mice. Mol. Cell. Biol. 7:1085-1090.

32. Watson, G., and K. Paigen. 1988. mRNA synthesis rates in vivo for androgen-inducible sequences in mouse kidney. Mol. Cell. Biol. 8:2117-2124.

33. Wilson, A. C., S. S. Carlson, and T. J. White. 1977. Biochemical evolution. Annu. Rev. Biochem. 46:573-639. 